\title{
EXPERIMENTS ON PORCELAIN SUSPENSION INSULATOR UNITS
}

\author{
BY J. CAMERON CLARK
}

\section{Abstract of Paper}

The author gives a very complete description of the experiments on porcelain suspension insulator units carried on at Stanford University by him and his assistants under the direction of Prof. H. J. Ryan. He explains the preliminary organization necessary, the scope of the tests, and the unusual equipment required to measure the very high resistance of sound, dry insulators. Preliminary resistance measurements were made on all normal batches of porcelain units and the results tabulated, as also were results obtained when the units were subjected to mechanical stress, to voltages ranging from 1,000 to 30,000 , to temperature variation. Another set of tests was made to determine the effect of moisture in insulators. Drying insulators for a few hours in an oven at 150 deg. cent. produced very conclusive results of the effect of moisture in lowering resistance. Attempts were made to water-log units by soaking, by soaking with a temperature cycle applied, by subjecting units under various conditions to a steam pressure of $60 \mathrm{lb}$., and by a vacuum treatment of insulators before soaking. A brief statement is given of the conclusions arrived at.

\section{Introduction, Origin of, and Organization for the Work}

HE WORK of Prof. Ryan. The work of Prof. Harris J. Ryan at Stanford University in the winter of 1915-16 demon. strated both the feasibility and the desirability of measuring the insulation resistance of suspension insulator units having resistances in the range between 5000 megohms and several millions of megohms. To illustrate: It was shown by Prof. Ryan that certain units having insulation resistances of, say, 15,000 megohms could be punctured in the air on 60-cycle voltage. The ordinary portable megger of 5000 -megohms maximum scale reading will give a reading of infinity for such a unit, as it is unable to differentiate between units of 6000 and $1,000,000$ megohms, whereas a dry, sound porcelain insulator will have a resistance of the order of 1,000,000 megohms or one "megameg-

Manuscript of this paper was received November 21, 1916.

*These values, as well as all other resistance values contained in this paper, are referred to a temperature of $20 \mathrm{deg}$. cent. unless otherwise mentioned. 
ohm". Prof. Ryan also disclosed the fact that some units become much lower in insulation resistance when subjected to prolonged soaking in water.

Organization for tests. This work stimulated much thought among high-voltage engineers and, in particular, it aided in crystallizing a desire among them to develop a method by which it would be possible to detect faulty units with certainty, thus rendering it possible to avoid their installation. Accordingly, a committee of engineers was formed in May, 1916 to undertake experimental investigations of suspension insulator units, having as their broad purpose the production of test methods by which to detect with certainty and celerity all units which are electrically weak. Obviously, there is much difference of opinion on the classification of insulators as electrically "weak" and "strong". It is held by the committee, however, that any unit which is either weak at time of test or gives any indication whatever of the capability of developing weakness through lapse of time is to be condemned as weak.

The financial support of the work has consisted in contributions from a number of the California power companies. These companies, besides certain insulator manufacturers, have contributed liberally in test-specimens which will be found illustrated and briefly described in connection with "Preliminary Resistance Measurements".

The facilities of the electrical laboratories of Stanford University were placed at the disposal of the committee during the three summer vacation months of June, July, and August, 1916; and the writer and assistants were employed during this period to prosecute the testing work.

\section{EXPERIMENTAL WORK}

Scope of Tests. In addition to the measurement of the insulation resistance of every insulator unit in the condition in which it arrived at the laboratory, the summer's work consisted largely in attempting to determine the influence of certain important physical conditions of the insulator units upon their insulation resistance. The physical conditions which have been thus investigated are; mechanical stress, electrical stress (using continuous voltage), temperature, absorbed moisture.

The High-Voltage Megger. Since the resistance of a sound, dry porcelain insulator at ordinary air temperature is exceedingly large (of the order of $10^{12} \mathrm{ohms}$ ), it became necessary to provide 
rather unusual equipment with which to measure this quantity. Without entering into a discussion of the possible apparatus for this purpose, it may suffice to say here that it was decided to employ 25,000 volts continuous pressure current through the insulator, and to use as sensitive a D'Arsonval type galvanometer as could be had conveniently, to measure the current.

The pieces of apparatus which, taken collectively, may be called the high-voltage megger are shown diagrammatically in Fig. 1. $\quad T_{1}$ is a $33-\mathrm{kv}$. transformer which supplies charge to the air condenser $C$, at high voltage through the kenotron $K . T_{2}$ is an insulating transformer through which the heating current is furnished to the cathode filament of the kenotron. The contin-

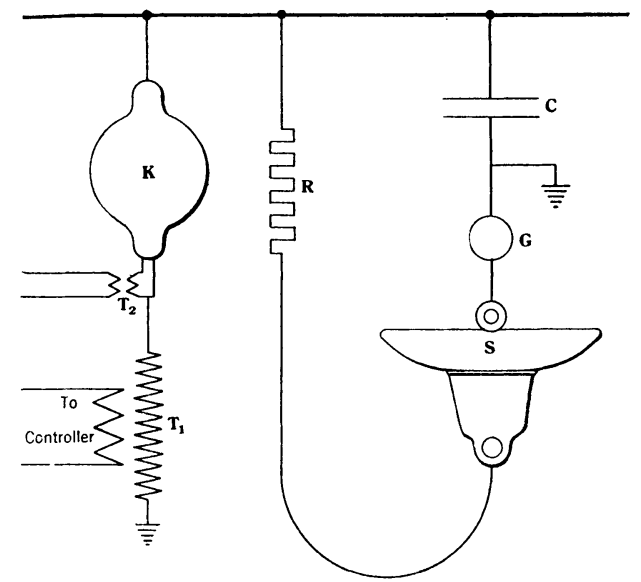

Fig. 1-High Voltage Megger-Connection Diagram

uous high voltage is impressed upon the insulator at $S$ through the resistance $R$ which is provided as a protection to the kenotron against a possible short-circuit of the load at $S . \quad R$ is adjusted to allow only full-load current for the kenotron to flow on such a short-circuit, and with 25,000 volts on the circuit. The galvanometer $G$ is connected in the test circuit next to ground. The connections from the low-voltage side of the insulator to the galvanometer are described in detail below.

The use of 25,000 volts on the insulator results in an amount of surface leakage vastly in excess of that which occurs with the 600 to 1000 volts ordinarily used in megger tests. Most of this leakage is in the form of corona, and hence cannot be eliminated by any amount of careful cleaning of the surface of the insulator. 
It is accordingly necessary to conduct all such strays directly off to ground by a path around the galvanometer. Fig. 2 shows the scheme used. Whenever possible, ordinary tap-water is used to make connection to uncemented porcelain blanks, and to make guard-rings, as it is very convenient in application. With units unprovided with petticoats, a felt ring saturated with water is laid on as a guard-ring, and the can guard is set directly on top of this felt ring. A grounded lead sheath protects the entire length of the wire running from insulator to galvanometer, while

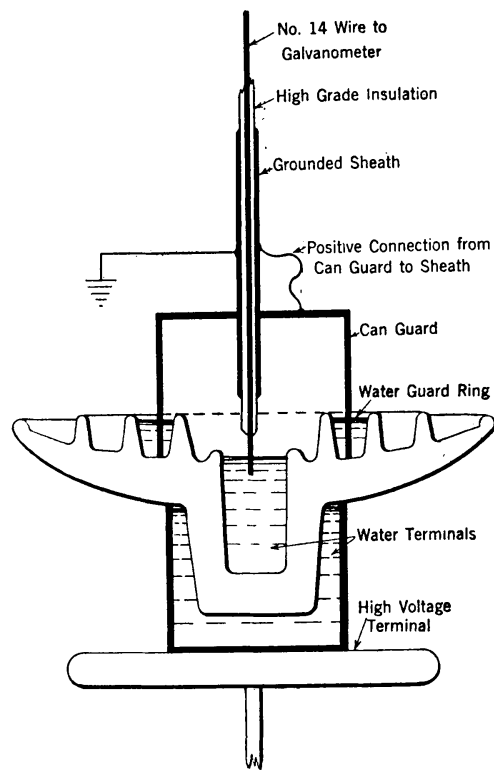

Fig 2-Details of Guarding SCHEME the instrument is remote enough from the high-voltage parts of the circuit to be immune from stray currents through the atmosphere.

Adjustment of the megger voltage is secured by means of an auto-transformer with multigap secondary feeding through a controller into the primary of the 33-kv. transformer, while a voltmeter connected across this primary serves to determine the megger voltage, a calibration curve of the megger in terms of the primary voltage having been secured by means of a 7-inch (17.7-cm.) sphere gap.

Preliminary Resistance Measurements. Table I is a summary of the resistance measurements made on all of the normal batches of porcelain units immediately upon their arrival at the laboratory. The $U K$ units are uncemented blanks of the same make and year as the assembled units of the $J$ series. The $U H$ units are blanks corresponding in every way to those used in the assembled $H$ units. The photographic reproductions, Figs. 3 to 10 inclusive, illustrate all the types of units listed in the table. Table I also contains letters designating which insulator units are from a common maker. To illustrate: Units $G, H$, and $H M$ were all made by the same manufacturer, $C$. It will thus be seen that the porcelain products of four different makers, $A, B, C$, and $D$ are represented in the tests. 
plate I.

A. I. E. E.

VOL. XXXVI, NO. 1

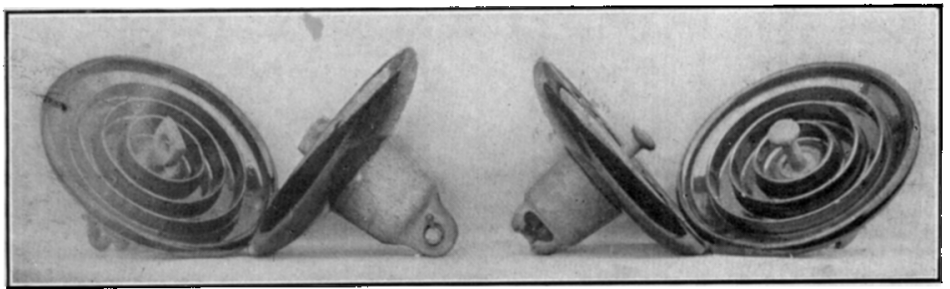

FIG. 3

FIG. 4

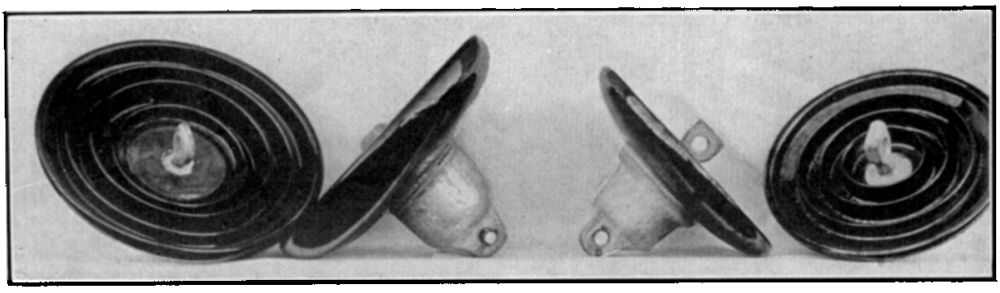

FIG. 6

FIG. 5

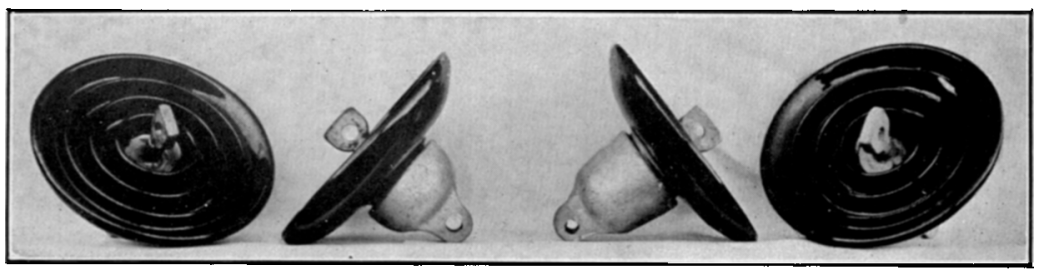

FIG. 7

FIG. 8

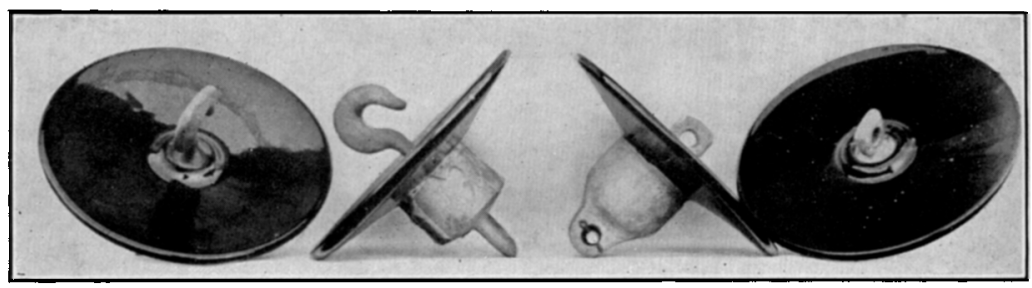

FIG. 9

FIG. 10

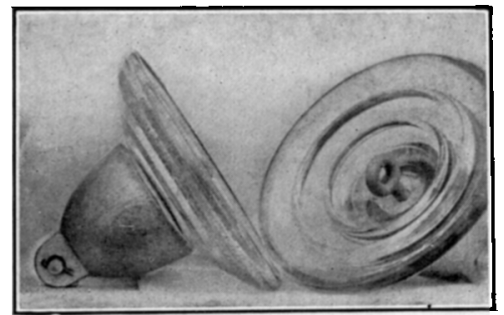

FIG. 13 



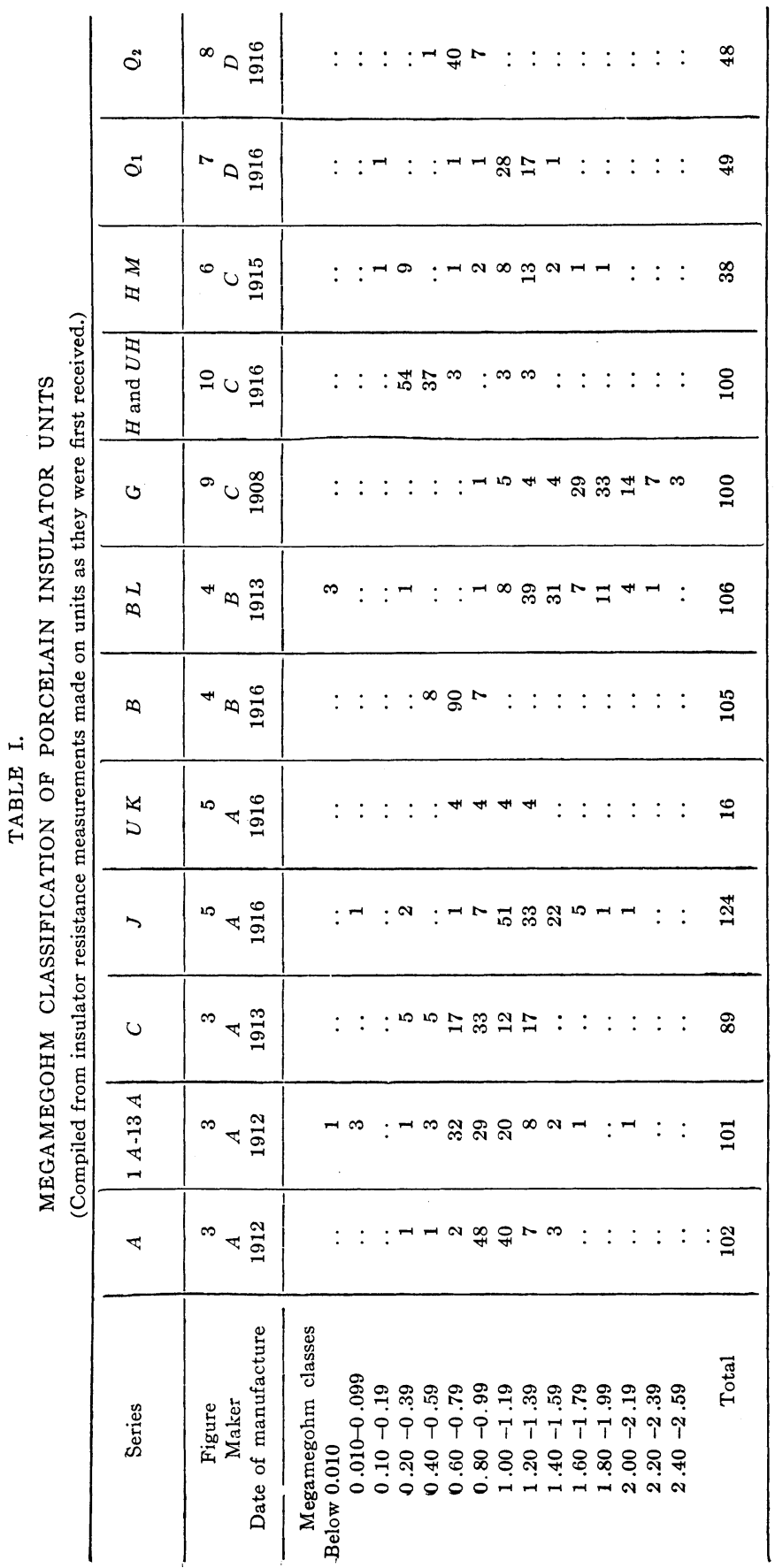


In addition to the units of Table I, reference is made in this paper to various members of three additional small groups of units; namely, the $U B, B M$, and $F$ groups. Of these the $U B$ and $B M$ units are specially selected soggy specimens of the same make and date as the $B L$ series of Table I. The $F$ units are of a new material, not porcelain. Fig. 11 shows the temperature-resistance characteristic of this material as exhibited by unit $F 5$. Fig. 13 is a photograph of an $F$ unit.

Pull-Resistance Studies. A testing machine was used to subject the units to mechanical stress to detemine whether this would affect their resistance. Pulls ranging from 0 to 5000 lbs. (22679. kg.) were applied to each kind of unit, but in no case was there any change in resistance from that obtaining for the unit in the mechanically unstressed condition.

Voltage-Resistance Studies. Some work was done using the high-voltage megger to ascertain whether the resistance of a unit is constant over the range 1000 to 30,000 volts. In any case where this source has been used, there has appeared to be practically no variation in insulation resistance over the range mentioned. However, some earlier work was done in the megging of very soggy units in which continuous voltages below 750 volts were used in order to hold the galvanometer current down to safe values. In every case where such a unit was later megged on 25,000 volts, the resistance thus determined is much lower than that obtained on the lower voltage. Table II shows results thus secured.

TABLE II

\begin{tabular}{|c|r|r|}
\hline Unit No. & Test Voitage & $\begin{array}{r}\text { Resistance, } \\
\text { megohms }\end{array}$ \\
\hline B L 19 & 110 & 13,000 \\
& 25,000 & 820 \\
5 A 6 & 415 & 21,000 \\
& 25,000 & 6,900 \\
B L 105 & 625 & 13,000 \\
& 25,000 & 8,300 \\
B L 68 & 635 & 8,300 \\
& 25,000 & 2,200 \\
8 A 4 & 730 & 60,000 \\
& 25,000 & 20,000 \\
8 A 2 & 740 & 73,000 \\
& 25,000 & 42,000 \\
\hline
\end{tabular}


It is not clear why there should be a difference between the resistance values obtained for these units at low voltage and at high voltage since quite a variety of low- and high-resistance units tested over a range of 1000 to 30,000 volts have shown no variation of resistance over that range.

Temperature-Resistance Studies. Early in the work it was brought forcibly to the attention of the test force that the temperature of an insulator is a factor of the greatest importance in its behavior under the megger test. To illustrate this point, Table III is presented.

TABLE III.

\begin{tabular}{|c|c|c|}
\hline Unit No. & $\begin{array}{c}\text { Resistance as first } \\
\text { measured, } \\
\text { megamegohms }\end{array}$ & $\begin{array}{c}\text { Resistance as later } \\
\text { measured, } 20 \\
\text { deg. cent. } \\
\text { megamegohms }\end{array}$ \\
\hline $1 A 3$ & 1.25 & 1.03 \\
\hline $1 A 4$ & 1.04 & 0.99 \\
\hline $1 A 5$ & 1.09 & 1.12 \\
\hline $1 A 6$ & 0.93 & 1.09 \\
\hline $1 A 7$ & 0.60 & 0.74 \\
\hline $1 A 8$ & 2.08 & 1.01 \\
\hline $2 A 1$ & 0.83 & 1.11 \\
\hline
\end{tabular}

The second column gives results which were obtained before the influence of temperature upon the resistance of an insulator was fully appreciated. The units had been lying in the hot sun for about an hour for the purpose of drying following a washing which had been given them. They had then been brought into the laboratory and laid on the floor for various lengths of time ranging from 15 to 45 minutes before being megged. It was then assumed that the room temperature (25 deg. cent.) could be taken as the temperature of the units without much error. The third column gives later results obtained after the units had reached a carefully determined steady temperature of $20 \mathrm{deg}$. cent. The lack of concord between the results in the second and third columns shows clearly the necessity for more careful work in this respect and, together with other similar observations, indicated the need of making a rather careful study of the resistance of porcelain as a function of temperature. An oven was therefore constructed which makes it possible to heat up eight units simultaneously and to megg them conveniently one after another on 25,000 volts continuous. All units rest on a common grate upon which is impressed the high voltage. Eight low voltage 
connections pass out through the thick heat-insulated wall of the oven to a terminal board at which the galvanometer lead is connected to any unit desired. The temperature is determined by 10 carefully calibrated resistance coils wound of No. 34 copper wire having heavy leads brought out for convenient connection to a Wheatstone's bridge. The coils are placed at the height of the porcelain of the units and are otherwise at locations so

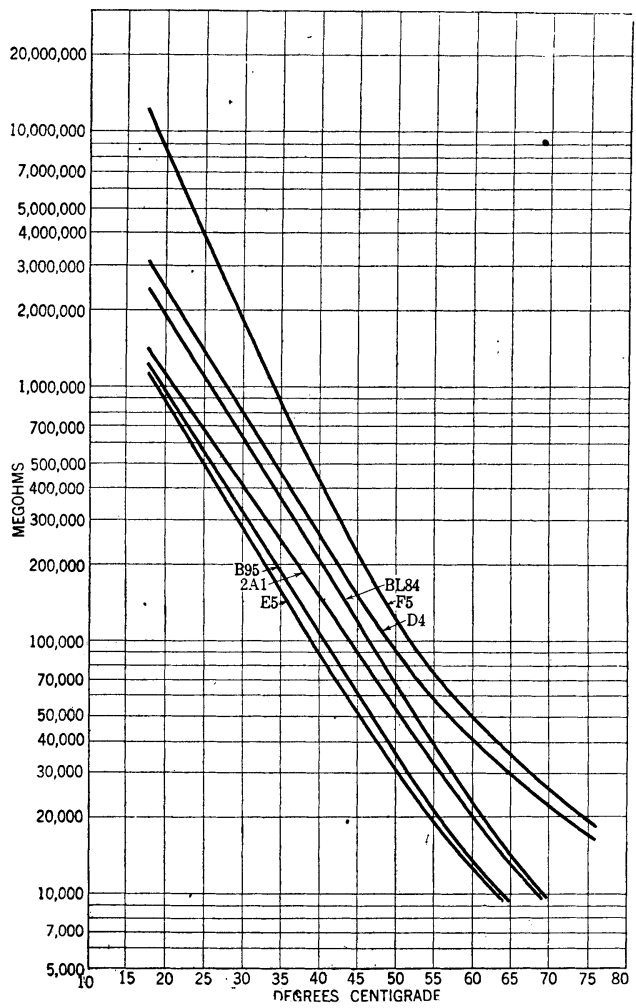

Fig. 11-Variation of Resistance with Temperature

chosen within the oven as to make it possible to judge of the resistance of a unit with a precision ranging from 0.2 deg. cent. at 25 deg. to 1 deg. at $65 \mathrm{deg}$.

The results of the study of six different insulator units are shown in the curves of Fig. 11. An exceedingly rapid rate of decrease of resistance with increasing temperature is shown by all the units, and this rate is substantially the same for all the different makes of porcelain insulators investigated. Fig. 12 is 
a curve derived from the temperature resistance curves of porcelain units which has been found very useful in reducing to a common temperature basis of $20 \mathrm{deg}$. cent. resistance measurements made over a temperature range of 17 to $27 \mathrm{deg}$. cent.

\section{Moisture in Insulators}

Results of Drying Out Insulators. That some high-voltage porcelain absorbs enough moisture to lower its resistance is shown conclusively by the results of drying numerous insulator units for a few hours in an oven at $150 \mathrm{deg}$. cent. All the insu-

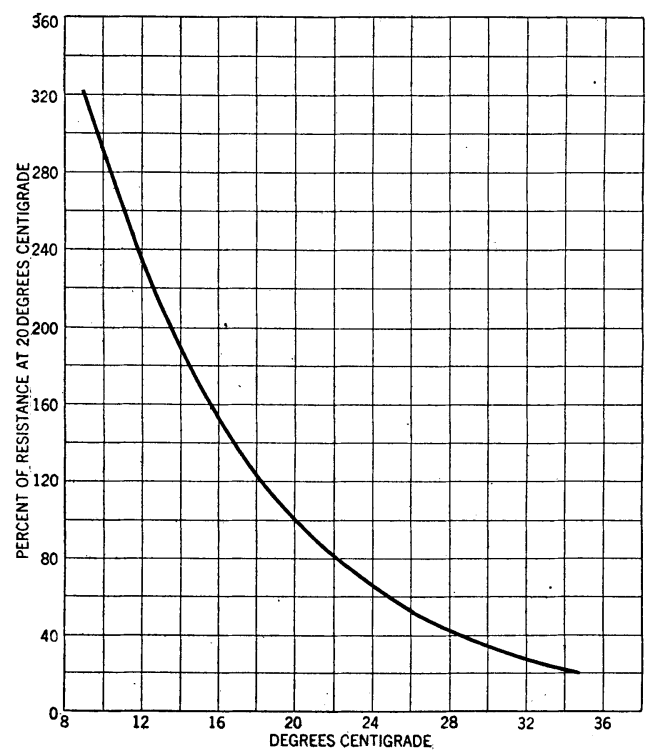

Fig. 12-Porcelain Insulator Temperature Reduction Curve

lators investigated in this way fall naturally into three classes (see Table IV) as determined by the effect of the drying upon their resistance; viz., (a) those practically unaffected by any amount of drying, (b) those raised in resistance by 20 to 400 per cent, (c) those enormously raised in resistance, i.e., hundreds or thousands of times. A result of this natural division of the units has been for the test force to call classes (a), (b), and (c) respectively "non-porous", " slightly porous", and "very porous".

Attempts to Water-log Units. It is obvious that a very easy laboratory test for the detection of porosity in an insulator is the high-voltage megger test, provided the insulator is already water 


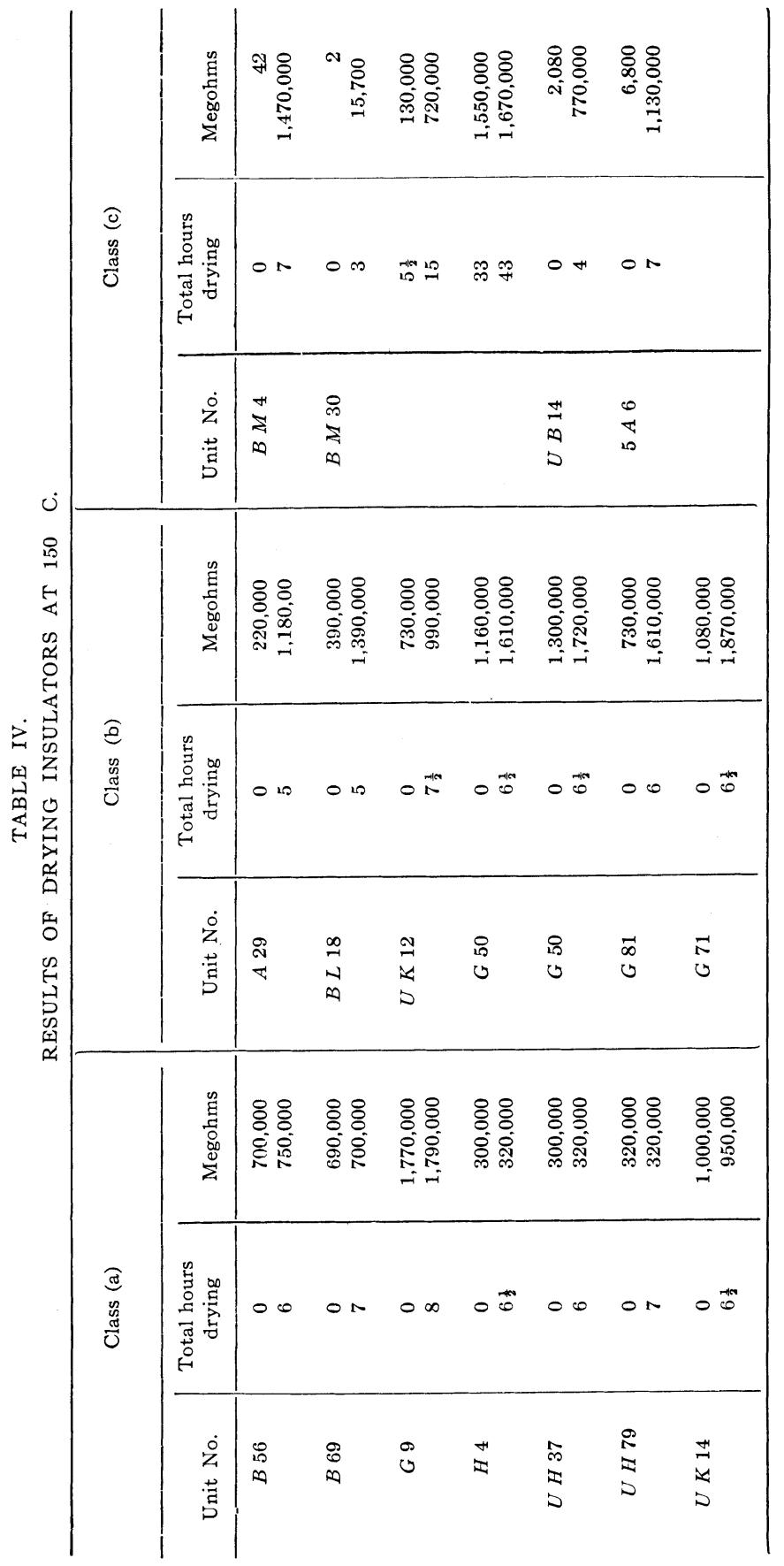


logged. However, many, if not all, very soggy units (i.e., units reading below infinity on the 5000 -megohm megger) may be raised by a few hours drying to an apparently perfect condition in which they pass a 60-cycle dry spark-over test in air. It has accordingly been regarded as essential that a method be found by which porous units may be made to take up water quickly inasmuch as any test which consumes weeks or months of time in order to establish porosity cannot be considered to have practical or commercial value.

Early in the work, the soaking of porcelain units in water at ordinary atmospheric temperatures was undertaken, but it became evident that, by this method, water enters wet-process porcelain units with extreme slowness, even in the case of units which have been called in the laboratory, "very porous".

It was then suggested that, along with the soaking, a temperature cycle be applied. It was the idea that there might exist a sort of breathing action caused by volumetric changes of the material under changing. temperatures which would draw water into the extremely attenuated pores of the porcelain. Accordingly, five units which were believed to have varying degrees of porosity were selected and put through the following cycle; Put into tub of water and water brought from $30 \mathrm{deg}$. cent. to boiling, 1 hour; water being boiled, $\frac{1}{2}$ hour; water being cooled to $30 \mathrm{deg}$. 1 hour, units cooled in "cold tank", (20 deg. cent.), $\frac{1}{2}$ hour. This cycle was repeated two or three times per day. The results are shown in Table V:

TABLE V.

“ACCELERATED SOAKING”-RESISTANCES IN MEGAMEGOHMS.

\begin{tabular}{|c|c|c|c|c|c|}
\hline Total cycles & $U B 3$ & $U B 5$ & $U B 13$ & $U B$ F4 & $U K 13$ \\
\cline { 2 - 6 } & 0.75 & 0.73 & 0.0085 & 0.53 & 0.80 \\
1 & 0.55 & 0.41 & 0.011 & 0.36 & 0.62 \\
2 & 0.66 & 0.57 & 0.030 & 0.39 & 0.80 \\
3 & 0.61 & 0.55 & 0.021 & 0.36 & 0.76 \\
5 & 0.66 & 0.84 & 0.046 & 0.36 & 1.27 \\
\hline
\end{tabular}

As shown by the table, the only positive effect of this process was to raise the resistance of some of the units treated. This is no doubt due to a rapid driving out of water from the porcelain during the boiling part of the cycle.

Another "accelerated soaking" test was next attempted in which the boiling part of the cycle was eliminated, the water being carried to a maximum temperature of $75 \mathrm{deg}$. cent. The 
same five units used in the previous test were subjected to this modified test. The results are shown in Table VI.

TABLE VI.

MODIFIED ACCELERATED SOAKING-RESISTANCES IN MEGAMEGOHMS.

\begin{tabular}{|c|c|c|c|c|c|}
\hline \multirow{2}{*}{ Total cycles } & $U B 3$ & $U B 5$ & $U B 13$ & $U B 14$ & $U K 13$ \\
\cline { 1 - 5 } & 0.82 & 0.72 & 0.032 & 0.34 & 0.99 \\
5 & 0.76 & 0.65 & 0.0039 & 0.18 & 1.01 \\
8 & 0.71 & 0.63 & 0.0021 & 0.115 & 0.98 \\
16 & 0.72 & 0.65 & 0.0011 & 0.072 & 0.94 \\
24 & 0.82 & 0.66 & 0.00074 & 0.025 & 0.99 \\
\hline
\end{tabular}

It is seen from Table VI that the rather porous units $U B 13$ and $U B 14$ are rapidly brought down in resistance by the 24 cycles of treatment, but that the slightly porous unit $U K 13$ has not been affected at all.

It was suggested that the entry of water into the pores of porcelain might be expedited by keeping one side of the porcelain exposed to the atmosphere while water is applied to the other, it being the theory that the application of water to both sides of the unit traps a certain amount of air within the pores effectually preventing the entire filling of the pores with water. To test this theory, two very porous units were selected and water was applied to one side of each. With a cemented unit, $B M 30$, the insulator was inverted and water was simply poured around the pin within the inner skirt of the unit and allowed to remain there for about two weeks. In the case of the other unit, $U B 18$, which is an uncemented porcelain blank, a rig was devised by which the pin cavity was filled with water and kept under $60 \mathrm{lb}$. per sq. inch $(4.2 \mathrm{~kg}$. per sq. cm.) pressure for about 30 hours. In neither case was there any material acceleration of the water absorption beyond that which would occur with ordinary soaking of the entire unit in water.

Since the negative results obtained in the application of water to one side of porcelain units may imply that the pores of the material are of such minute section that water enters them rapidly when in gaseous form, it was concluded to try the application of steam to one side of a porous unit. The test rig mentioned in the previous paragraph was therefore modified to permit the unit to be heated from the outside hot enough to generate steam within the pin cavity while the latter is kept filled with water at $60 \mathrm{lb}$. per square inch pressure. Thus steam at $60 \mathrm{lb} .(27.2 \mathrm{~kg}$.) pressure is applied to the inner surface of the pin cavity. Unit $U B 18$ was given two hours of this steam treatment. Megohm 
readings taken just before the test, and again as soon afterward as the unit had become cold are respectively 310,000 and 1050 . This shows a remarkably rapid lowering of the resistance. This test was also applied to unit $U K 13$ which had been considered to be a slightly porous unit from the results of the first "accelerated soaking" test, see Table V. However, megger readings taken just before three hours treatment of the unit and afterward as soon as the unit had become cold show in each case a resistance of 0.85 megamegohms.

Vacuum treatment just before soaking has been tried with a number of units believed to be of varying degrees of porosity. The results of one such test are shown in Table VII.

TABLE VII.

VACUUM AND PRESSURE TREATMENT-RESISTANCES IN MEGAMEGOHMS.

\begin{tabular}{|c|c|c|c|c|}
\hline \multirow[t]{2}{*}{ Unit No. } & \multicolumn{3}{|c|}{ Resistance in megamegohms } & Remarks on previous status of unit. \\
\hline & Aug. 16 & Aug. 17 & Aug. 18 & \\
\hline$U B 2$ & 0.00052 & 0.00028 & 0.00019 & $\begin{array}{l}\text { Considered "very porous" because of } \\
\text { rapid lowering of its resistance in cold } \\
\text { water soaking. }\end{array}$ \\
\hline$C 76$ & 0.123 & 0.0101 & 0.0029 & $\begin{array}{l}\text { Considered "very porous" because its } \\
\text { resistance lowered rapidly when stored on } \\
\text { concrete floor in a cool place. }\end{array}$ \\
\hline$C 1$ & 0.79 & 0.94 & 1.00 & $\begin{array}{l}\text { Considered "slightly porous" as its resis- } \\
\text { tance rose decidedly when stored in a } \\
\text { warm, dry place. }\end{array}$ \\
\hline G5 50 & 1.69 & 1.61 & 1.74 & $\begin{array}{l}\text { Considered "slightly porous" because its } \\
\text { resistance rose somewhat due to drying } \\
\text { in oven. }\end{array}$ \\
\hline$G 60$ & 1.69 & 1.79 & 1.63 & Same as $G 50$ \\
\hline$G 71$ & 1.69 & 1.50 & 1.61 & Same as $G 50$ \\
\hline G 81 & 1.51 & 1.45 & 1.42 & Same as $G 50$. \\
\hline
\end{tabular}

The values of resistance for Aug. 16 were obtained just prior to placing the units in the vacuum tank. On Aug 16, the units were put under a 25 -inch $\left(63.5 \mathrm{~mm}\right.$.) vacuum for $1 \frac{1}{2}$ hours, and while the vacuum was maintained, water was run into the tank until the units were covered. The water was allowed to remain over the units at atmospheric pressure over night ( 15 hours), and the results for Aug. 17 were then obtained. A 25 -inch vacuum was again applied to all the units for five hours which was followed up immediately by water, the vacuum being maintained until the tank was filled with water. The water was kept under the supply pressure of $60 \mathrm{lb}$. per sq. inch above atmosphere

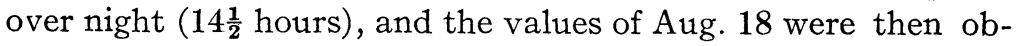
tained. As shown by the table, decided lowering of resistance occurred only in the cases of the "very porous" units. 
With but two exceptions, the methods which have been tried in attempting to water-log units rapidly have been fairly successful in the cases of units known to be very porous. These two exceptions are the ordinary soaking in cold water and the attempt to accelerate water-logging by heating and cooling wherein boiling occurred during the cycle. However, no method has yet been found by which the slightly porous units can be made to take water rapidly. That efforts to this end have failed is remarkable in view of the fact that the water may be driven out of such units in a very few hours by heating them at $150 \mathrm{deg}$. cent. Whether these insulators would deteriorate in actual line service is a debatable question, the discussion of which lies outside the scope of this paper.

\section{Conclusion}

Much of the work of the summer has been concerned with the study of moisture absorption in porcelain insulators as indicated by their insulation resistance. This is largely due to the fact that few other characteristics of the specimens submitted have seemed so much worth while investigating as their porosity. In this connection, it is important to note that very little trouble with cracking due to expansion of metal parts is in evidence among the specimens, even among the older batches of units wherein little attention was evidently given to this subject. Some 60 assembled units of various makes have been subjected to temperatures ranging from $110 \mathrm{deg}$. to $150 \mathrm{deg}$. cent.-much higher temperatures than are ever encountered in service. Among these units were 30 selected as being most likely to crack owing to bad design wherein no provision was made at the base of the cap next to the disk for expansion of the cap. Out of the 60 , only 3 units have failed by cracking; namely, Nos. $B L 94$, $C 9$, and $C 76$,- all of old design.

Inasmuch as the real factors which contribute to the weakness of many porcelain insulators are now much better appreciated, it is felt that some progress has been made toward achieving the broad purpose of the investigation; namely, to develop ready, sure and simple methods by which to detect the weak insulator. It is at the same time realized that a great amount of work remains to be done, and it is hoped that many others will devote themselves to this problem which it seems so necessary to solve if confidence is to attend the continued use of the porcelain highvoltage insulator. 